\title{
Waste Related Pollutions and Their Potential Effect on Cancer Incidences in Lebanon
}

\author{
Sahar K. Azar ${ }^{1}$, Safa S. Azar ${ }^{2}$ \\ ${ }^{1}$ Department of Life and Earth Sciences, Faculty of Sciences, Fanar Campus, Lebanese University, Beirut, \\ Lebanon \\ ${ }^{2}$ Institut de Neurosciences de Montpellier, Hôpital Saint Eloi, 80 Avenue Augustin Fliche, Montpellier, France \\ Email: sahar.azar@hotmail.com
}

Received 9 February 2016; accepted 8 May 2016; published 11 May 2016

Copyright (C) 2016 by authors and Scientific Research Publishing Inc.

This work is licensed under the Creative Commons Attribution International License (CC BY). http://creativecommons.org/licenses/by/4.0/

c) (i) Open Access

\begin{abstract}
Pollution represents an important threat to human health. Waste pollution with its adverse health risks, mainly cancer incidences, is one of the main issues present in Lebanon. Random disposal of wastes is instilling a complex and challenging situation that is affecting the entire population. Here, a comprehensive study is presented along with collected data addressing the correlation between long-term exposure to the different forms of pollution and the chances of being affected with cancer. Lebanon, a country currently facing an extensive garbage crisis, is undergoing alarming surges in pollution rates. Inevitably, these environmental factors become chief elements in influencing disease statistics. It is therefore of urgent importance to seek all solutions possible while raising awareness in order to reduce life threatening risks.
\end{abstract}

\section{Keywords}

Waste Pollution, Waste Management, Cancer, Health, Lebanon

As defined by the World Health Organization (WHO), "health is a state of complete physical, mental and social well-being and not merely the absence of disease or infirmity". The issue of public health has been the subject of interest to many throughout the past years. With time, it became increasingly more pressing to dissertate the measures that ought to be taken in order to maximize the quality of living and provide worldwide education regarding the expansion in the risk factors related to higher incidences of diseases and injuries.

In the last century, the topic of pollution has been taking a huge turn. The introduction of new contaminants is not only manipulating the status of the environment and altering the climate, but also primarily affecting public 
health with direct, alarming effects. These effects include an increase in the incidence of various diseases, mainly cancer. WHO has estimated that environmental exposures contribute to $19 \%$ of cancer incidences worldwide [1].

Recently, cancer is taking the spotlight for being the second leading cause of death after heart disease and stroke. Evidently, more than 12 million people around the world are diagnosed with cancer. Few recent studies have strikingly reported a positive association between pollution (in all its forms) and the occurrence of cancer.

As a general overview, land pollution as well as water pollution occurs when waste from various sources is not being properly disposed. Wastes generated by industries can be classified into two main categories: nonhazardous wastes having similar characteristics to municipal wastes, and industrial wastes having the characteristics of hazardous wastes as referred to in the Basel convention. Thereby, non-biodegradable materials can remain intact for thousands of years while leaching chemicals into the ground. Along with these chemicals, domestic wastes, industrial effluents, agricultural wastes, marine dumping and radioactive wastes are the causes of water pollution. Since the incineration of waste contaminates the air; it subsequently affects land and water through significant precipitation.

Duly, waste pollution and its consequences seem to have a direct effect on cancer. Clinical and observational studies show a substantial correlation between the exposure to pollution and the incidence of cancer in different populations worldwide. Studies based on this correlation demonstrate that environmental pollution is contributing to DNA methylation leading to genome instability [2] [3] and somatic mutations [4] not to mention increasing carcinogenesis.

In addition, air pollution is proved to be an important contributor to many types of cancer in the US [5]. Air pollution may also be considered as a cardiovascular risk factor [6]. In Beijing, the smog-addled capital, cancer is now the leading cause of death, with lung-cancer rates rising by 60 percent from 2001 to 2010 . A previous study showed that people who live in places with high levels of air pollutants have a $20 \%$ higher risk of death caused by lung cancer than people who live in less-polluted areas [7]. Raaschou-Nielsen, O. et al. [8] showed that long exposure to traffic-related air pollution is related to a leukemia risk in the Danish population. Further, García-Pérez et al. [9] confirmed the relation between ovarian cancer mortality and industrial pollution.

Some studies have shown an increase in the frequency of diverse types of cancer near hazardous waste sites [10]. For example, consider the southern region of Italy. This area alone has experienced an increase in rates of lung and liver cancer as well as other diseases that exceed the overall national Italian average [11]. On the one hand, these clinical observations were the product of long term exposure to waste which was mainly caused by illegal disposal by the Camorra criminal organization. On the other hand, the lack of remediation of the polluted sites and the mismanagement of persistent wastes are also linked to those diseases.

Other studies conducted in the region of Naples show that Italy has a high percentage of bladder cancer compared to the rest of Europe. This study was confirmed by the elevated levels of polychlorinated Dibenzo-P-Dioxins and Dibenzofurans (PCDD/Fs) and Polychlorinated Biphenyls (PCBs) whose major source is the combustion of municipal wastes [12]. Dioxins are formed during combustion processes, and are more soluble in fats than in water and then tend to be built up in fats within plants and animals. Consequently, these substances persist in the environment, followed by an uptake into the food chain. Waste incineration is considered as a main source of food contamination when emissions are disposed on farmlands.

Landfill sites are conceived for the disposal of waste materials. They are the simplest, cheapest and most cost-effective methods of the disposing of waste [13]. Nonetheless, it remains a relevant source of groundwater contamination for the foreseeable future [14].

In Thailand, in March 2014, a big fire at a waste landfill site was accompanied by a colossal toxic smoke. Studies have shown that an increase in lung cancer mortality risks can be linked to this waste crisis [15]. Previous studies have also showed that despite the fact that sulfur dioxide is not classified as a carcinogen, a relationship between the exposure to sulfur dioxide and lung cancer does exist [16].

It is worth mentioning that the World Health Organization's "2010 Global Burden of Disease" study found that air pollution contributed to 1.2 million premature deaths worldwide; 220,000 of which are cancer related including 140,000 mortalities caused by lung cancer. Three years later, and for the first time, WHO's International Agency for Research on Cancer classified air pollution as a cause of cancer. And in late 2013, China's youngest lung cancer patient, an 8 year old girl, was considered a victim of air pollution [17]. The girl, who was living near a busy road, was exposed to PM2.5 pollution, the smallest and most dangerous type of airborne particles. These fine harmful particles are considered to be risky because they lodge deep in the lungs and can enter the blood stream. The same report mentions that $11 \%$ of digestive system cancers may stem from unsafe drinking 
water [17].

Waste composition varies with a person's lifestyle and economic status. Taking Lebanon's case more specifically, most industries are light manufacturing ones, mainly belonging to eight branches only: food and beverage $(20 \%)$, fabricated metal products $(16 \%)$, non-metallic mineral products $(12 \%)$, furniture $(11 \%)$, clothes and dyeing fur $(10 \%)$, wood products $(10 \%)$, leather products $(6 \%)$ and textiles $(4 \%)$ [18]. But, precariously, Lebanon, according to the National Cancer Registry (NCR), has the highest cancer prevalence rate in the Eastern Mediterranean Region.

Granted, this statistic has evoked many scientists to take interest in studying cancer incidence cases regionally. As in 1998, a study conducted in Chekka, North Lebanon has linked the emissions caused by industrial plants to be the source of three kinds of gases: $\mathrm{CO}_{2}, \mathrm{CO}$ and $\mathrm{NO}_{2}$, viewed as the main cause of pulmonary cancer [19].

Later on, data collected between 2003 and 2007 showed that the number of incident cases is progressively increasing [20]. A recently published data study, based on previous ones and on data from the actual period, predicts that overall cancer incidence rates for both males and females will significantly increase by 2020: from $0.16 \%$ in 2008 to $0.23 \%$ in 2020 for men and from $0.19 \%$ to $0.28 \%$ for women [21].

In 2010, high percentage of $\mathrm{CO}_{2}$ emissions in the atmosphere was reported to cause $40 \%$ of the death toll in Lebanon due to cancer and heart attacks [22]. Inescapably, recent studies have shown higher risk for cancer development in traffic policemen who are exposed to benzene and 1,3-butadiene at the roadside in central Beirut on day to day basis [23].

The population growth and the diminishing of land areas are aggravating the waste management issues to the point of a national crisis. According to SWEEP-Net, the major percentage of municipal solid waste is land filled or dumped and only a minor percentage, 17 percent, is recovered through sorting and composting. In the absence of a well-defined legislation and the lack of regular control, the industrial wastes are being mixed with the municipal wastes leading to a direct impact on the population. Additionally, and ironically, the lack of political consensus on critical waste management issues has always led to emergency measures where the most politically acceptable ones are adopted at the expense of the environmental solutions. Despite the fact that Lebanon has signed several conventions related to waste disposal (hazardous and non-hazardous), legislation related to waste management are probably underestimated by the Lebanese society and it seems that the government does not have any strategy regarding this issue. Unfortunately, there is no comprehensive and organized system of solid waste management in Lebanon.

Solid waste is one of the most acute and visible environmental issues in Lebanon, especially considering its impact on health and environment. These environmental problems have been increasing for the past few years while the state lacks the means and the will to solve them. Approximately for the past ten months, Lebanon has been facing a "garbage crisis" with the current political situation. Tons of garbage has continued to pile up on the streets of Lebanon's capital Beirut as the government struggles to deal with a situation that is quickly turning into an environmental crisis for the country. Lebanese authorities are not forming an emergency committee to reduce waste and figure out sustainable solutions. Temporary solutions included incineration, accumulation in landfills, and dumping in open-air spacious locations. However such random solutions may lead to various health hazards.

Furthermore, this ongoing garbage crisis will shortly affect the surface water, the groundwater, the atmosphere, the soil and consequently the crops. Garbage left out on the streets will decompose and vaporize into the atmosphere leading to a bigger new threat: the acid rain. The most common and expected human health problems are the ones related to gastro-intestinal, dermatological and respiratory issues. Since the main sources of drinking water are wells and springs, the result is a high incidence of waterborne diseases. The direct effect on agriculture and respectively on health was proved by a Chinese study regarding these particular kinds of pollution (soil and water pollution) in different departments of China [24]. To date, however, no comprehensive studies have been carried out to assess the public health impacts of hazardous waste in Lebanon. According to a national television report, the number of patients hospitalized for diseases that could be related to the garbage crisis has increased almost 50\% in the last month. Diarrhea, nausea, vomiting and abdominal pain are just a few of a large number of symptoms. Furthermore, even though there are not any present studies conducted on the relationship between waste pollution and cancer in Lebanon, previously mentioned pollution crises reports nevertheless link the two.

In addition, hazardous wastes bring harm to human health when the metal pollutants will eventually enter the underground water and the food chain. These include cancers, respiratory and hearth diseases, genetic defects, 
damages to the central nervous system and congenital anomalies. While the untreated chemicals found in the atmosphere and to which the Lebanese population are exposed will cause an increase in cancer rates. Moreover, these rates may be enhanced with the consumption of toxin carcinogen polluted products.

An Italian study [25] proved that the exposure to municipal waste can lead to an increase in liver cancer cases. Also statistically significant clusters were detected for liver, lung, leukemia and soft tissue sarcomas. Plus, testis cancer showed a significant trend with the index of waste-related exposure. While some other studies from other countries did not find a correlation between waste exposure and cancer incidence [26], different other health risks can be related to such exposure.

Urban waste is leading to the release of numerous and dangerous volatile organic compounds (VOCs) [27]. These VOC are major air pollutants that include formaldehyde, benzene and several others. Their presence in the environment can lead to an interaction with some air components such as the ozone leading to a serious health risk.

The main disposal method in Lebanon is land filling which covers an estimated $53 \%$ of generated Municipal solid waste. These wastes, once collected, are thrown in uncontrolled dumpsites scattered around the entire country. And it seems that the attempts to reach a practical solution to the urban waste accumulation in different landfills around Lebanon do not look promising for the foreseeable future. Methane gas formed in the internal parts of the dumpsite regularly creates fires and uncontrolled burning. High emissions of polychlorinated Dibenzo-P-Dioxins and polychlorinated Dibenzofurans (PCDDs/PCDFs) [28], two of the significant environmental pollutants, are caused by this kind of waste disposal. Several of the dumpsites are situated in proximity of rivers and streams as well as urban communities. However, the Lebanese government's endeavor to burn these piled wastes is only ridiculously increasing health risks. About 10 percent of mercury emissions come from open burning, as well as 40 percent of polycyclic aromatic hydrocarbons (PAHs). Such pollution can cause lung and neurological diseases, and have been linked to heart attacks and some cancers.

Now the prominent question on our minds is as follows: Are we more susceptible to cancer? The International Agency for Research on Cancer (IARC) and the Environmental Protection Agency (EPA) reported that dioxins are probable human carcinogens, but noted that non-cancer effects (reproduction and sexual development, immune system) may pose a greater threat to human health. It is distressing, rather frightening that Lebanon, a small country with little industrial factories, has cancer incidence rates comparable to the ones reported in major industrialized countries in Europe and the US [21].

In 1992, the United Nations Environment Program's (UNEP) reported that some 4.7 million people live in Lebanon, including foreigners. They produce some 0.7 to $0.9 \mathrm{~kg} /$ resident/day, meaning a total of about 3800 tons per year of solid wastes for the whole country. In 2014, and according to the "CIA World Factbook - Lebanon" the Lebanese population is almost 6 million with 1.1 million Syrian refugees and half a million of Palestinian refugees. They generate around 2.5 million tons of waste per year, where each resident produce approximately 0.8 to $1.2 \mathrm{~kg}$ /day. Solid wastes are projected to increase by an annual rate of $1.65 \%$ [29]. Of this generated waste, the organic fraction in Lebanon is very high, it forms $55 \%$, while $16 \%$ are papers and cardboard, $14,5 \%$ are plastic and $17 \%$ come from divers waste. Notably, this composition changes according to areas and season. Adding to the hazardous waste stream, Lebanon annually generates 20,000 tons of medical waste, of which 5000 tons is considered infectious [18]. Most of these types of wastes require specific treatment in order to avoid health risks and disease outbreak.

Health risks are not in this case just the result of the different forms of pollution. It is this waste's accumulation that can lead to the spread of some diseases through rodents, insects and even rain and inundations. Arif and Doumani [30] insisted on the fact that the accumulation of solid waste in different regions can lead to the attraction of rodents and insects and that during the rainy periods, stagnant water ponds are commonly found on such sites and increase the likelihood of vector-borne disease transmission.

Waste generation is correlated with the rapid urbanization and the limited awareness of the health risks associated to waste among the Lebanese. The trash crisis is not solely the most serious problem, rather the little space accorded to landfills in such a small country. And since widespread recycling and composting program has yet to be introduced, Lebanese tend not to use recycled and degradable materials unaware that excessive packaging and non-degradable items will end up in dumpsters and landfills.

One of the solutions that were provided is the application of the principle of decentralization in terms of waste treatment where each municipality or village has the responsibility for the establishment of centers for sorting, composting and assembly grouping. Up until now there is no waste recycling industries and main landfills are 
quickly filled and shut down, this means that the urban waste will be accumulated in all the different Lebanese regions leading to an increase risk of pollution of the different water resources as well as the soil.

Thus, the environmental protection and landfill upgrading should occur as soon as possible; Lebanon is really in need for the development of a systematic, comprehensive, and ecological solid waste management program in order to minimize the health problems jeopardizing the population. Emerging organizations should start working on introducing recycling in the region. And since industrial and hazardous wastes are being mixed with municipal solid wastes, industries should join efforts in order to create specific industrial waste treatment facilities which could be an action supported by the central government.

The "garbage crisis" in Lebanon is but one example of the political deals that take place behind the scenes there and elsewhere, in which politicians exchange favors at the expense of citizens. This political bargaining is not unique to Lebanon, but also governments around the world are failing to provide adequate solutions to deal with garbage. Thus for example, in Dhaka in Bangladesh, garbage is lining the streets where municipal waste management service has capacity to only collect just 60 percent of the trash. Re-mentioning Naples, Italy case, the local mafia has been dumping toxic waste illegally in the region. This region has come to be known as the "Triangle of Death," with waste-related pollution linked to higher cancer rates compared to other similar regions. Regarding the situation in Lebanon, the fear of a prolonged untreated waste disposal management lies in the risks which threaten the health of Lebanese people, whether at the level of short term diseases or the exposure to carcinogens and the potential increasing in cancer incidence rates.

The health effects related to improper waste disposal are many. Rapid solutions can be promoting waste reduction at source, sorting of rubbish including composting organic material, recycling nonorganic waste and supporting reuse. Hence, the sustainable waste management is feasible in Lebanon. Consequently, the placement in a properly managed sanitary landfill to produce energy for the waste that can be neither prevented nor recycled or composted can be done. The conversion of wastes to produce energy is known as Waste-to-Energy (WTE) process. In 2009, these forms of waste recovery represent global volumes of about one billion tons per year-roughly equivalent of $25 \%$ of all solid waste generated annually worldwide [31].

These solutions involve environmental, social, economic and health benefits. Since convenient waste management processes will avoid environmental degradation and decrease the probability of diseases, cancer and premature death and the consequential costs. As long as no efforts are made to change and improve the solid waste management, wastes will remain a considerable threat to the public health.

\section{Acknowledgements}

We thank Ms Lena Awad for improving the use of English in the manuscript.

\section{References}

[1] Vineis, P. and Xun, W. (2009) The Emerging Epidemic of Environmental Cancers in Developing Countries. Annals of Oncology, 20, 205-212. http://dx.doi.org/10.1093/annonc/mdn596

[2] Cao, Y. (2015) Environmental Pollution and DNA Methylation: Carcinogenesis, Clinical Significance, and Practical Applications. Frontiers of Medicine, 9, 261-274. http://dx.doi.org/10.1007/s11684-015-0406-y

[3] Ali, A.H., Kondo, K., Namura, T., Senba, Y., Takizawa, H., Nakagawa, Y., et al. (2011) Aberrant DNA Methylation of Some Tumor Suppressor Genes in Lung Cancers from Workers with Chromate Exposure. Molecular Carcinogenesis, 50, 89-99. http://dx.doi.org/10.1002/mc.20697

[4] Yu, X.J., Yang, M.J., Zhou, B., Wang, G.Z., Huang, Y.C., Wu, L.C., et al. (2015) Characterization of Somatic Mutations in Air Pollution-Related Lung Cancer. EBioMedicine, 2, 583-590. http://dx.doi.org/10.1016/j.ebiom.2015.04.003

[5] Grant, W.B. (2009) Air Pollution in Relation to US Cancer Mortality Rates: An Ecological Study; Likely Role of Carbonaceous Aerosols and Polycyclic Aromatic Hydrocarbons. Anticancer Research, 29, 3537-3545.

[6] De Rosa, M. and Cerini, M. (2015) Toxic Urban Waste's Assault on Cardiovascular Risk. IJC Metabolic \& Endocrine, 6, 36-42. http://dx.doi.org/10.1016/j.ijcme.2015.01.008

[7] Grens, K. (2011) Air Pollution Tied to Lung Cancer in Non-Smokers. Thomas Reuters, New York.

[8] Raaschou-Nielsen, O., Ketzel, M., Poulsen, A.H. and Sørensen, M. (2015) Traffic-Related Air Pollution and Risk for Leukaemia of an Adult Population. International Journal of Cancer, 138, 1111-1117.

[9] García-Pérez, J., Lope, V., López-Abente, G., González-Sánchez, M. and Fernández-Navarro, P. (2015) Ovarian Cancer Mortality and Industrial Pollution. Environmental Pollution, 205, 103-110. 
http://dx.doi.org/10.1016/j.envpol.2015.05.024

[10] Griffith, J., Duncan, R.C., Riggan, W.B. and Pellom, A.C. (1989) Cancer Mortality in US Counties with Hazardous Waste Sites and Ground Water Pollution. Archives of Environmental Health: An International Journal, 44, 69-74. http://dx.doi.org/10.1080/00039896.1989.9934378

[11] Triassi, M., Alfano, R., Illario, M., Nardone, A., Caporale, O. and Montuori, P. (2015) Environmental Pollution from Illegal Waste Disposal and Health Effects: A Review on the "Triangle of Death". International Journal of Environmental Research and Public Health, 12, 1216-1236. http://dx.doi.org/10.3390/ijerph120201216

[12] Di Lorenzo, G., Federico, P., De Placido, S. and Buonerba, C. (2015) Increased Risk of Bladder Cancer in Critical Areas at High Pressure of Pollution of the Campania Region in Italy: A Systematic Review. Critical Reviews in Oncology/Hematology, 96, 534-541. http://dx.doi.org/10.1016/j.critrevonc.2015.07.004

[13] Barrett, A. and Lawlor, J. (1995) The Economics of Solid Waste Management in Ireland. Economic and Social Research Institute (ESRI) Research Series.

[14] Allen, A. (2001) Containment Landfills: The Myth of Sustainability. Engineering Geology, 60, 3-19. http://dx.doi.org/10.1016/S0013-7952(00)00084-3

[15] Wiwanitkit, V. (2014) Waste Landfill Site Fire Crisis in Thailand; Sulfur Dioxide Pollution and Estimation of Cancer Risk. South Asian Journal of Cancer, 3, 185-186. http://dx.doi.org/10.4103/2278-330X.136813

[16] Katanoda, K., Sobue, T., Satoh, H., Tajima, K., Suzuki, T., Nakatsuka, H., et al. (2011) An Association between LongTerm Exposure to Ambient Air Pollution and Mortality from Lung Cancer and Respiratory Diseases in Japan. Journal of Epidemiology, 21, 132-143. http://dx.doi.org/10.2188/jea.JE20100098

[17] Xu, B. (2014) China's Environmental Crisis. Council on Foreign Relations.

[18] SWEEP-Net (2014) Country Report on the Solid Waste Management in Lebanon.

[19] Youssef, C. (1998) Industrial Pollution and Its Impacts on Public Health in the Chekka Area.

[20] Salim, M., Adib, M. and Daniel, J. (2003) National Cancer Registry: Cancer in Lebanon 2003. Ministry of Public Health, Beirut.

[21] Shamseddine, A. (2014) Cancer Trends in Lebanon \& Projections to 2020. H. a. Health, Ed.

[22] Azar, M. (2010) Air Pollution in Lebanon. Signature, 3, Q1.

[23] Borgie, M., Garat, A., Cazier, F., Delbende, A., Allorge, D., Ledoux, F., et al. (2014) Traffic-Related Air Pollution. A Pilot Exposure Assessment in Beirut, Lebanon. Chemosphere, 96, 122-128. http://dx.doi.org/10.1016/i.chemosphere.2013.09.034

[24] Lu, Y., Song, S., Wang, R., Liu, Z., Meng, J., Sweetman, A.J., et al. (2015) Impacts of Soil and Water Pollution on Food Safety and Health Risks in China. Environment International, 77, 5-15. http://dx.doi.org/10.1016/j.envint.2014.12.010

[25] Fazzo, L., Santis, M.D., Mitis, F., Benedetti, M., Martuzzi, M., Comba, P., et al. (2011) Ecological Studies of Cancer Incidence in an Area Interested by Dumping Waste Sites in Campania (Italy). Annali dell'Istituto Superiore di Sanità, 47, 181-191.

[26] Gouveia, N. and Prado, R.R.D. (2010) Health Risks in Areas Close to Urban Solid Waste Landfill Sites. Revista de Saúde Pública, 44, 859-866. http://dx.doi.org/10.1590/S0034-89102010005000029

[27] Vilavert, L., Figueras, M.J., Schuhmacher, M., Nadal, M. and Domingo, J.L. (2014) Formaldehyde: A Chemical of Concern in the Vicinity of MBT Plants of Municipal Solid Waste. Environmental Research, 133, 27-35. http://dx.doi.org/10.1016/j.envres.2014.04.041

[28] Lemieux, P.M., Lutes, C.C., Abbott, J.A. and Aldous, K.M. (2000) Emissions of Polychlorinated Dibenzo-p-Dioxins and Polychlorinated Dibenzofurans from the Open Burning of Household Waste In Barrels. Environmental Science \& Technology, 34, 377-384. http://dx.doi.org/10.1021/es990465t

[29] Bank, B. (2015) Solid Waste Management in Lebanon. Sweep-Net, Ed.

[30] Arif, S. and Doumani, F. (2014) Lebanon, Cost Assessment of Solid Waste Degradation in Beirut and Mount Lebanon. Tunis.

[31] Chalmin, P. and Gaillochet, C. (2009) Du rare à l'infini: Panorama mondial des déchets: 2009: Economica. 